\title{
SIX YEARS AS PRESIDENT
}

\author{
A Valedictory by the former ICCA President
}

David Levy

Our Editor-in-Chief has asked me to present a short account of my tenure as ICCA President for the period 1986-1992. It would be very pleasant for any outgoing President to report that every one of his aims, stated when he took office, had been achieved. Regrettably it is not possible for me to do this because the ICCA did not double its membership as I had hoped. Nevertheless, looking back to the June 1986 issue of the ICCA Journal I think that I can justifiably claim that in all other respects the activities of the ICCA and the world of computer chess in general have exhibited the trends I had hoped for.

In retrospect it was, perhaps, over-optimistic of me to expect that the ICCA could double its membership. Although there are tens or even hundreds of thousands of people in the world who have a strong interest in computer chess, it is only a small minority of them who can benefit from the excellent technical articles which form the core of our Journal. Those devotees whose interest lies more in the relative merits of the various commercially available chess programs have their "own" publications, such as the German magazine ComputerSchach und Spiele, which boasts around 7,000 readers.

One of the main reasons for my desire to see the ICCA membership grow is simply explained - MONEY! Although all of the ICCA office bearers are volunteers, who contribute their time and other resources for the ICCA's benefit, the costs associated with producing a prestigious scientific publication such as the ICCA Journal exceed the income that the Association receives from its membership fees. It is therefore imperative to find additional sources of revenue, including sponsors, to ensure that the ICCA remains a viable organisation. In this task I feel that considerable success has been achieved during the past 6 years.

When I became President the ICCA inherited an unfortunate legacy from the Secretary/Treasurer of the previous administration - we were almost completely out of cash. In order to rectify this, I took a leaf out of FIDE's book. The International Chess Federation has, for many years, charged tournament and match organisers a fee for the right to hold official FIDE competitions. The ICCA soon started to do the same, and as a result I am delighted to report that we now have a very healthy cash surplus. This does not mean that we shall rest on our laurels, far from it. I have promised Tony Marsland that I shall continue to search for sponsorship funds for future ICCA events and am pleased to report that we already have an offer of sponsorship for the 1993 World Microcomputer Chess Championship.

In addition to raising money from computer tournament sponsors the ICCA has also received regular and generous donations from computer manufacturers (Hegener + Glaser and Saitek), and from anonymous donors. I would like to record my formal thanks to all of these supporters for everything they have done to help the ICCA. Long may it continue.

Referring back once again to 1986, one of my stated aims was to see more recognition by FIDE and by national chess federations of the achievements of the strongest computer programs. I had hoped by now that FIDE would recognize some programs as FIDE Masters or even International Masters. This has not happened but the first steps on this path were taken by FIDE at its annual Congress in Manila last June. Computer programs are now eligible for official FIDE ratings and their presence in "human" chess tournaments is officially recognized. FIDE does not permit human players to refuse to be paired against a computer program. Unfortunately, FIDE's implementation of this particular stride of progress leaves much to be desired. FIDE is asking for unacceptable payments to be made by the computer manufacturers or programmers who wish to enter their programs in human international competitions. Hopefully these teething troubles can be overcome in the not-too-distant future. If not, FIDE's decision will turn out to be a serious retrograde step, as it will eliminate much of the manversus- machine chess that has become a regular feature of the chess world in recent years and at the same time it will deny tournament organisers the sponsorship funds which they had hitherto received from computer manufacturers. 
In other areas, computer chess has progressed well during the past six years. The amount of space devoted to computer chess in the chess magazines and newspaper columns has increased significantly. In Britain, for example, The Times gives over the whole of its weekly chess column to computer chess from time to time, and devotes considerable space to the reporting of the Computer Olympiads and other computer-games contests. In many countries, such as Germany, France, Spain, the USA, Sweden and Holland, there are magazines devoted entirely to computer chess. There are also many important chess magazines all over the world which devote space on a regular basis to computer games. All of this extra publicity reflects the corresponding increase that has taken place in the number of computer-chess tournaments, as well as the number of important human tournaments in which computers have been encouraged to participate. We can safely assume that this trend will continue as computer programs gain in strength and increase their penetration of the commercial market.

Finally, a comment on the progress that has been made since 1986 in the goal of defeating the human World Chess Champion. On the one hand there have been some notable successes by the strongest chess programs. Deep Thought's outstanding result at Long Beach, where it defeated (amongst others) Bent Larsen (and later, in a play-off game, Tony Miles), demonstrated that when it is playing "on form" the world's strongest program is genuinely of Grandmaster strength. In contrast, Deep Thought's results have been inconsistent and the world of computer chess eagerly awaits the next generation of the hardware, which DT's designers hope will push it near to Kasparov's strength. In the meantime, it was a pleasure for me to witness the well-earned success achieved by Ed Schröder in Madrid, where his recently renamed program "Chessmachine Schröder" took the World Championship title ahead of many systems that used more powerful hardware. This clearly shows that in computer chess the importance of good software should not be underestimated. Schröder was reported as saying that he had recently made a change to his program which resulted in a surprising improvement in playing strength - around 60 ELO points. The world of computer chess needs only a few more ideas of similar power, and Kasparov can start to shake in his boots.

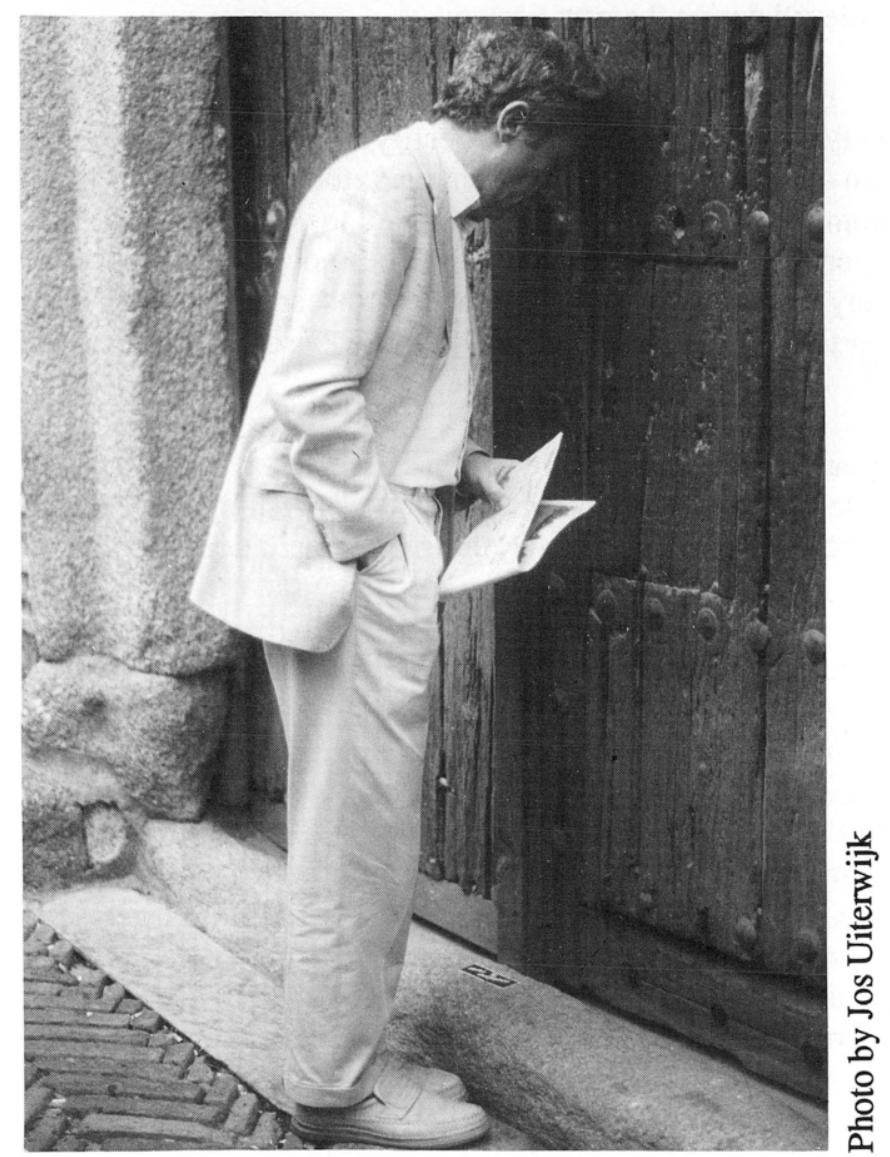

TWO TERMS, NO MORE.

David Levy, the outgoing President, in front of El Greco's house, Toledo (November 26, 1992). 